\title{
Regulation of prolactin secretion during the estrus in rats: possible role of glucocorticoids
}

\author{
Constanza M López-Fontana, María E Maselli, Florencia E G de Di Nasso, Carlos M Telleria ${ }^{1}$ \\ and Rubén W Carón \\ Instituto de Medicina y Biología Experimental de Cuyo (IMBECU), CONICET, CCT-Mendoza, 5500 Mendoza, \\ Argentina and ${ }^{1}$ Division of Basic Biomedical Sciences, Sanford School of Medicine of The University of South Dakota, \\ Vermillion, South Dakota 57079, USA \\ Correspondence should be addressed to R W Carón; Email: rcaron@mendoza-conicet.gob.ar
}

\begin{abstract}
Mifepristone (MIF) administration to cycling rats at proestrus induces hypersecretion of prolactin (PRL) at the following estrus. We aimed to assess whether this effect is due to the antiprogesterone or antiglucocorticoid action of MIF and to help underscore the nature of the circulating hormone(s) regulating PRL secretion at estrus. Female cycling rats in proestrus were treated with vehicle; the progesterone (Pg) and glucocorticoid receptor antagonists, MIF (5 mg/kg) or ORG-33628 (5 mg/kg); the glucocorticoid agonist dexamethasone (DEX; $27 \mathrm{mg} / \mathrm{kg}$ ) \pm MIF; or the inhibitor of steroid synthesis aminoglutethimide (AG; $150 \mathrm{mg} / \mathrm{kg}$ ) \pm MIF. The animals' blood was sampled the same day at $1800 \mathrm{~h}$ and at $1800 \mathrm{~h}$ of the following day to assess for circulating PRL and Pg levels. To distinguish antiglucocorticoid from antiprogesterone effects of MIF, we administered a highly specific neutralizing antibody against Pg. None of the antagonists modified serum PRL values at proestrus but increased PRL levels at estrus. DEX decreased the secretion of PRL at proestrus, yet the effect was entirely blocked by MIF. Furthermore, DEX decreased PRL at estrus in a MIF-reversible manner, suggesting that adrenal corticoids during proestrous may regulate PRL secretion at estrus. AG increased PRL secretion at estrus, whereas its association with MIF produced an even higher response. PRL concentration at estrus was not modified by the antiprogesterone antibody, suggesting that the effect of MIF is a consequence of its antiglucocorticoid effect and not due to its antiprogesterone properties. In conclusion, PRL secretion in the afternoon of the estrus is most likely regulated by glucocorticoids through an inhibitory action.
\end{abstract}

Reproduction (2011) 142 477-485

\section{Introduction}

Most studies on the hormonal regulation of prolactin (PRL) release have focused on the role of the ovarian steroids (Freeman et al. 1972, Caligaris et al. 1974, Arbogast \& Ben Jonathan 1990). However, accumulated evidence indicates that the adrenal gland is also able to regulate PRL secretion (Brann et al. 1990, Putnam et al. 1991). Previous studies have indicated that in ovariectomized (OVX) and estrogen-primed rats, serum PRL increased after adrenalectomy or mifepristone (MIF) treatment, while the administration of an antiprogesterone antibody (Pg-Ab) had no effect, suggesting that adrenal glucocorticoids negatively regulate estrogen-induced PRL release in OVX rats (Caron et al. 1994). Moreover, this inhibitory effect is evident at $1300 \mathrm{~h}$ but not at $1800 \mathrm{~h}$, suggesting that in addition to the well-known diurnal rhythm in endogenous secretion of corticoids (Dickmeis 2009), diurnal changes in the sensitivity of neuronal mechanisms regulating PRL secretion to corticoids may take place (Kiem et al. 1995, Caron et al. 1997).
The antiprogesterone/antiglucocorticoid MIF is a powerful agent that has contraceptive effects acting at different levels of the reproductive axis. In cycling rats, the administration of MIF blunts the primary surges of $\mathrm{LH}$ and FSH (Sanchez-Criado et al. 1992, Spitz \& Bardin 1993) and blocks the secondary surge of FSH (Knox \& Schwartz 1992, 1993, Szabo et al. 1996). Administration of MIF throughout the estrous cycle is associated with altered gonadotropin secretion and altered responsiveness of the follicles to gonadotropins, resulting in the suppression of the next expected ovulation (van der Schoot et al. 1987, Uilenbroek 1991, Knox \& Schwartz 1993). Moreover, a dramatic inhibition of the sexual receptivity and unsuccessful implantation, preceded by a reduction in $\mathrm{LH}$ and $\mathrm{PRL}$ secretion, lead to fertility impairment after a single dose of MIF administered before the preovulatory surge of LH (Telleria et al. 1997). Also, MIF administration to cycling rats during proestrus induces a surge of PRL secretion during the following estrus, suggesting that $\mathrm{Pg}$, corticosterone, or both steroids may regulate PRL secretion during the day of the estrus (Telleria et al. 1997). MIF has a high binding 
affinity for Pg and glucocorticoid receptors (Philibert \& Teutsch 1990). ORG-33628 (ORG), in turn, is a very potent and selective antiprogestin with a remarkably high ovulation-inhibitory activity; this difference in potency is species and/or target organ dependent. The binding of ORG to the Pg receptor is twice as high as that of MIF, whereas its binding to the glucocorticoid receptor is 25 times lower than that of MIF. Furthermore, the activity of ORG to interrupt pregnancy in rats is 16 times higher than that of MIF (Kloosterboer et al. 1995), whereas the antiglucocorticoid activity of ORG in rats is about eight times lower than that of MIF. These differences between MIF and ORG allowed us to investigate, to certain extent, the nature of the circulating steroid hormones that control PRL secretion during the rat estrus, by comparing the effects of both anti-steroid hormone drugs. It is important to note that the comparison between the effects of the less specific antagonists, MIF and ORG, and the effect of a specific neutralizing antiserum against $\mathrm{Pg}$, although it is not a direct approach to determine antiglucocorticoid actions, it is a useful indirect tool because, as described in previous studies (Tebar et al. 1995, Caron et al. 1997, Salicioni et al. 1997), it excludes the participation of Pg on the regulation of pituitary hormones.

The purpose of this study was to determine whether the hypersecretion of PRL on estrus as a consequence of the administration of MIF on proestrus is due to MIF acting as antiprogesterone or as antiglucocorticoid, with the final purpose of making evident the nature of the circulating hormones regulating PRL secretion during estrus.

\section{Results}

\section{Vaginal smears}

No changes in the transition from proestrus to estrus were observed as evaluated by vaginal smears in animals receiving MIF, ORG, dexamethasone (DEX), aminoglutethimide (AG), or a Pg-Ab on the day of proestrus.

\section{PRL secretion}

No change in serum PRL was observed during the afternoon of proestrous in rats treated with the Pg and corticoid antagonists MIF or ORG. However, DEX administration on proestrus significantly decreased $(P<0.05)$ serum PRL concentration and this effect was reverted by MIF (Fig. 1A). A significant increase $(P<0.05)$ in the circulating levels of PRL was observed at $1800 \mathrm{~h}$ on the estrous day as a consequence of the administration of MIF or ORG the previous day (Fig. 1B). Moreover, the administration of the glucocorticoid agonist DEX on proestrus decreased PRL values $(P<0.05)$ at the afternoon of estrous in a MIF reversible manner (Fig. 1B), suggesting that circulating adrenal
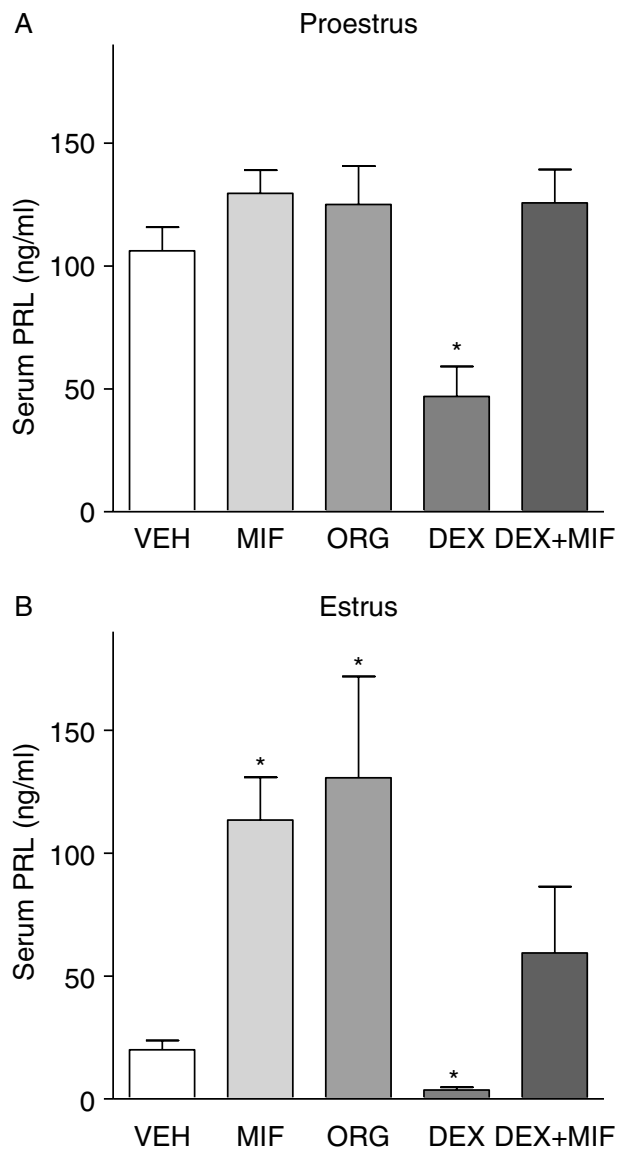

Figure 1 Serum PRL levels in rats treated during proestrus with mifepristone (MIF), ORG-33628 (ORG), dexamethasone (DEX), or DEX + MIF. Results are shown at $1800 \mathrm{~h}$ on proestrus (A) and on estrus (B). Control groups are vehicle-administered rats. Each value is the mean \pm s.E.M. of six to nine rats. ${ }^{*} P<0.05$ compared to control (VEH). One-way ANOVA (ANOVA I) and Bonferroni's test were used for multiple comparisons.

corticoids during proestrus may be involved in the regulation of PRL secretion at estrus.

To confirm the participation of glucocorticoids in the regulation of PRL secretion, we used AG to decrease the synthesis of glucocorticoids of adrenal origin. Treatment with AG increased serum PRL concentration significantly $(P<0.05)$, similar to MIF (Fig. $2 A)$. When both anti-hormones (i.e. MIF and AG) were given to the same animals at proestrus, a summation of effects was observed on serum PRL concentration $(P<0.001$, Fig. 2A).

To define the nature of the steroid-regulating PRL secretion, a specific Pg-Ab was used. Figure 2B shows that no change in serum PRL concentration was induced by the Pg-Ab when compared to treatment with normal rabbit serum (NRS) at proestrus and estrus. These results support the data shown in Fig. 1B, suggesting that adrenal corticoids play a role in the regulation of circulating PRL levels during the afternoon of estrus. 

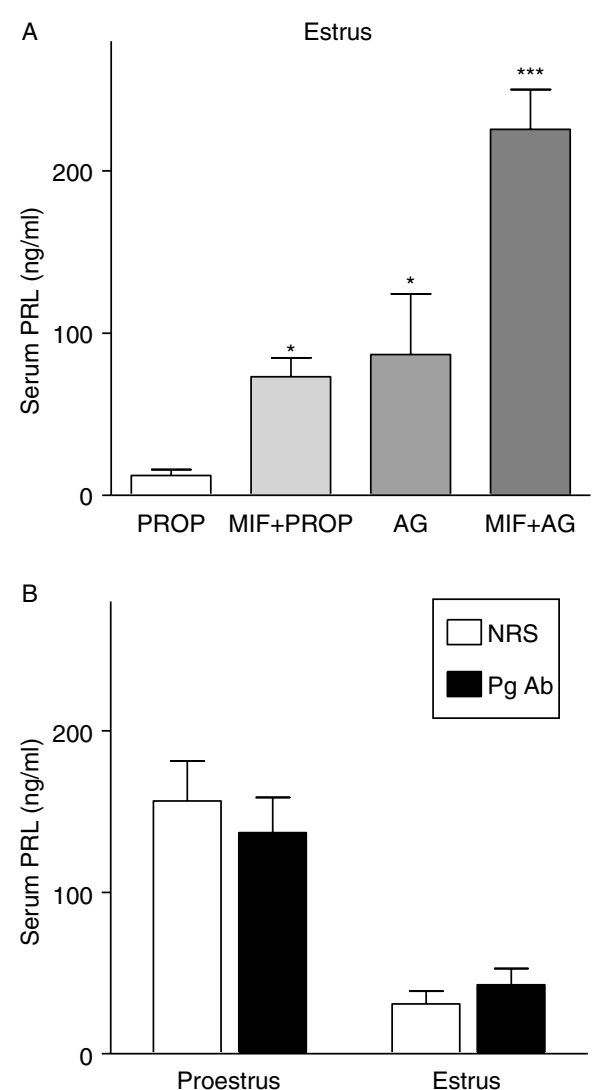

Figure 2 (A) Serum PRL levels at $1800 \mathrm{~h}$ on estrus in rats treated during proestrus with aminoglutethimide (AG), mifepristone plus propylene glycol (MIF+PROP), or MIF+AG. Control groups are PROPadministered rats. Each value is the mean \pm s.E.M. of six to nine rats. ${ }^{*} P<0.05$ and ${ }^{* * *} P<0.001$ compared to control. One-way ANOVA (ANOVA I) and Bonferroni's test were used for multiple comparisons. (B) Serum PRL levels at $1800 \mathrm{~h}$ on proestrus and estrus in rats treated with normal rabbit serum or anti-Pg antibody. Each value is the mean \pm s.E.M. of six to nine rats. One-way ANOVA (ANOVA I).

\section{Circulating levels of Pg}

We measured serum Pg concentrations to study whether the changes in PRL levels induced by the different treatments were consequence of modifications in $\mathrm{Pg}$ secretion. At $1800 \mathrm{~h}$ proestrus, serum Pg was increased as a consequence of the previous administration of both antagonists, MIF and ORG; instead, DEX caused a decrease in Pg levels $(P<0.01$, Fig. 3A). The latter effect is probably due to the decline in serum PRL levels induced by the corticoid. Similar results were observed during the day of estrus, yet with higher changes induced by the drugs considering the lower basal levels of circulating Pg (Fig. 3B).

As expected, administration of $\mathrm{AG}$ on proestrus induced a significant decrease in serum Pg concentration at estrus (Fig. 4A). The effect of the Pg-Ab on serum Pg levels shown in Fig. 4B demonstrates a significant reduction $(P<0.01)$ in free circulating Pg on both days of the estrual cycle.

\section{Uterine weight}

To verify the antiprogestin efficiency of MIF and ORG, we studied their effects on the uterus, where Pg opposes the actions of estrogens preventing estrogen-induced ballooning of the uterine horns. Ballooning can be easily evaluated by weighing the uterus after the hormonal treatment. Both steroid antagonists (i.e. MIF and ORG) significantly increased the weight of the uterine horns $(P<0.001)$, showing their efficacy in blocking Pg actions in the organ, while DEX had no effect (Fig. 5A).

MIF also augmented uterine weight when combined with propylene glycol (PROP; vehicle of AG), but it did not induce ballooning associated with AG (Fig. 5B), probably due to the blockage of estrogen synthesis; this is likely consequence of the fact that $A G$ inhibits the aromatase responsible for converting androgens into estrogens. Interestingly, the Pg-Ab caused a significant $(P<0.001)$ increase in uterine weight, suggesting that by sequestering Pg from the circulation treatment with the $\mathrm{Pg}-\mathrm{Ab}$ allows estrogen to stimulate fluid accumulation in the uterine cavity without having the opposition of $\mathrm{Pg}$ activity (Fig. 5C).

\section{$L H$ and FSH secretions}

The surge of $\mathrm{LH}$ at $1800 \mathrm{~h}$ proestrus was partially prevented by the administration of MIF $(P<0.05)$, but it was not modified by ORG. DEX, in turn, blocked the preovulatory peak of $\mathrm{LH}(P<0.05)$, and this effect was in part reversed by MIF (Fig. 6A). Basal levels of LH during the afternoon of estrus were significantly increased by both Pg antagonists $(P<0.001)$, yet LH was not modified by DEX (Fig. 6B). None of the treatments applied varied the circulating levels of FSH during proestrus or estrus (results not shown).

\section{Discussion}

The profile of PRL secretion throughout the estrous cycle has been studied extensively. Plasma concentrations of PRL are low from the evening of estrous until the afternoon of proestrus when there is a surge in the secretion of this hormone (Butcher et al. 1974). This surge of PRL temporally coincides with the preovulatory surge of $\mathrm{LH}$ and has three phases consisting of an early sharp peak, a later prolonged plateau, and a termination phase (Arbogast \& Ben Jonathan 1988). Controversial results have, however, been reported for PRL secretion on the day of estrus. Many authors described low basal levels of PRL throughout this day (Neill 1970, Smith et al. 1975, Arbogast \& Ben Jonathan 1988, Shimokawa et al. 1990), while some others have found instead high PRL levels during the afternoon of estrous (Butcher et al. 1974, Yen \& Pan 1998). These elevated PRL levels occasionally observed in the afternoon of estrus are generally attributed to a stressful stimulus related to the 

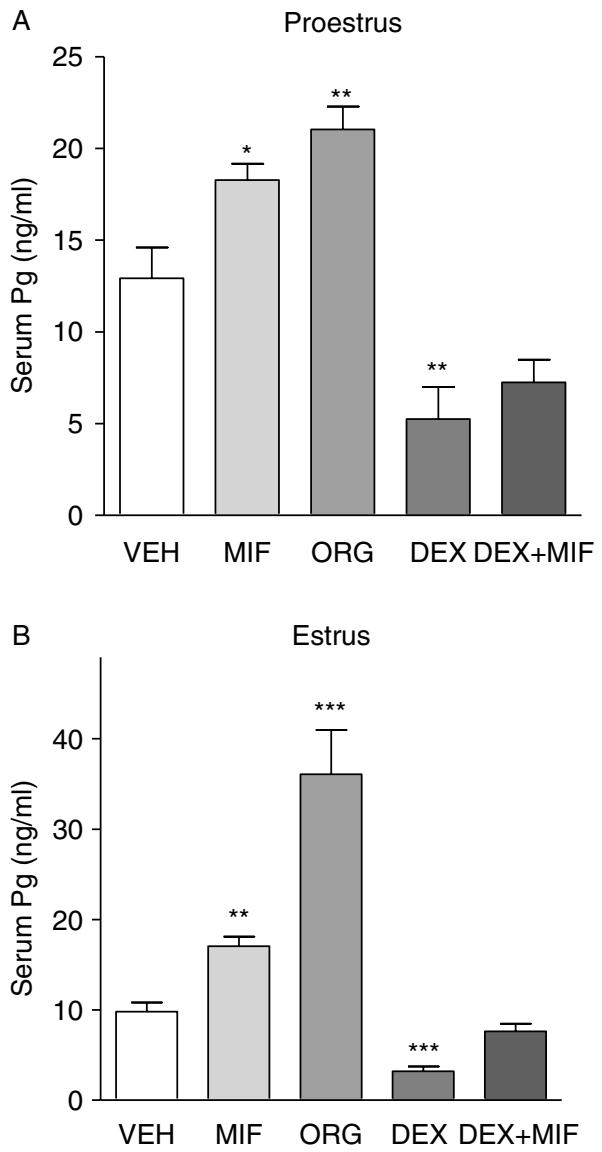

Figure 3 Serum progesterone (Pg) levels in rats treated during proestrus with mifepristone (MIF), ORG-33628 (ORG), dexamethasone (DEX), or DEX+MIF. Results are shown at $1800 \mathrm{~h}$ proestrus (A) and estrus (B). Control groups are vehicle-administered rats. Each value is the mean \pm S.E.M. of six to nine rats. ${ }^{*} P<0.05,{ }^{* *} P<0.01$, and ${ }^{* * *} P<0.001$ compared to control. One-way ANOVA (ANOVA I) and Bonferroni's test were used for multiple comparisons.

method and frequency of blood sampling (Gala 1990). For these reasons, it has been considered that the afternoon of proestrus is the only time in which a major surge of PRL secretion occurs (Freeman et al. 2000). Nonetheless, a secondary peak of PRL secretion during the afternoon of estrous has been described in cannulated female rats and related to the circulating levels of estradiol (Szawka \& Anselmo-Franci 2004). Yet, the participation of other steroids during proestrus and estrus that may regulate PRL secretion during estrus has been scarcely studied. Adrenal steroids, and particularly corticosterone, are potential regulators of estrual cyclerelated changes in plasma PRL concentration. In fact, corticosterone levels change in plasma throughout the estrous cycle, showing the lowest daily concentration at estrus, rising progressively over the following 3 days, and reaching a maximum the afternoon of proestrus, paralleling PRL secretion (Atkinson \& Waddell 1997). The present results provide new evidence for the regulation of rat PRL secretion during the day of estrus by glucocorticoids, which are in agreement with our previous findings showing that PRL secretion is inhibited by adrenal glucocorticoids in OVX and estrogen-treated rats (Caron et al. 1994, 1997).

MIF is a synthetic 19-nor steroid having potent antiprogestin and antiglucocorticoid properties as a consequence of its high binding affinity for both Pg and glucocorticoid receptors (Philibert \& Teutsch 1990). ORG, in turn, is a very potent and selective antiprogestin with a remarkably high-ovulation inhibitory activity (Kloosterboer et al. 1995). The differences between the antagonists allowed us to investigate, to certain extent, the nature of the circulating steroid hormones that control PRL secretion during the estrus in the rat.
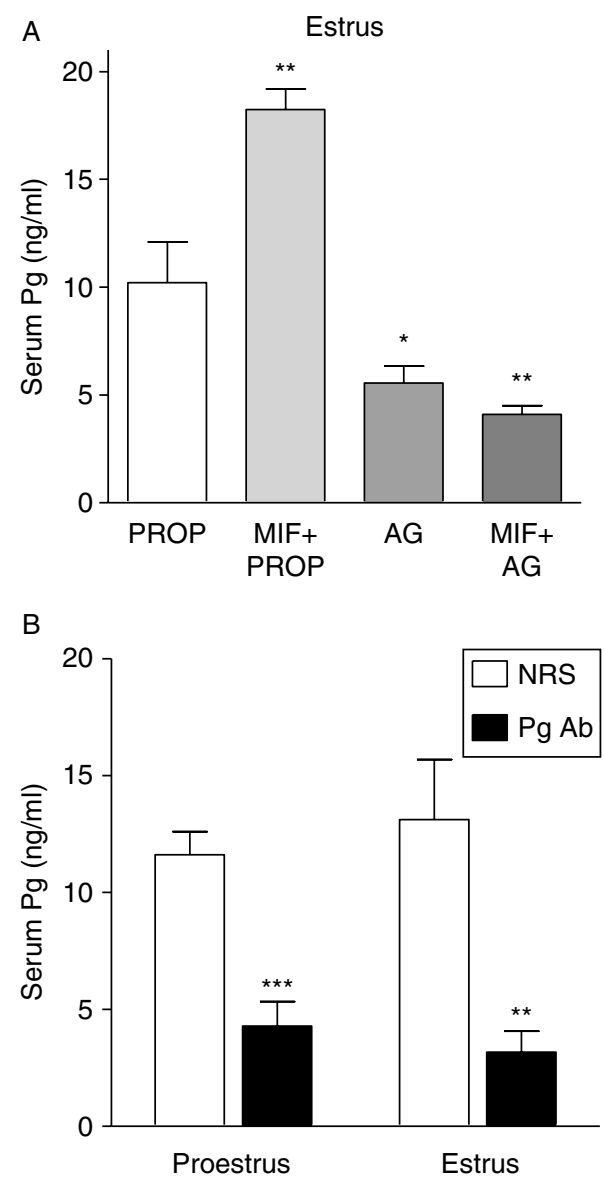

Figure 4 (A) Serum levels of progesterone (Pg) at $1800 \mathrm{~h}$ estrus in rats treated during proestrus with aminoglutethimide (AG), mifepristone plus propylene glycol (MIF+PROP), or MIF +AG. Control groups are PROP-administered rats. Each value is the mean \pm s.E.M. of six to nine rats. ${ }^{*} P<0.05$ and ${ }^{* *} P<0.01$ compared to control. One-way ANOVA (ANOVA I) and Bonferroni's test were used for multiple comparisons. (B) Serum Pg concentrations at $1800 \mathrm{~h}$ proestrus and estrus in rats treated with normal rabbit serum or anti-Pg antibody. Each value is the mean \pm s.E.M. of six to nine rats. ${ }^{* *} P<0.01$ and ${ }^{* * *} P<0.001$ compared to control. One-way ANOVA (ANOVA I) and Bonferroni's test were used for multiple comparisons. 

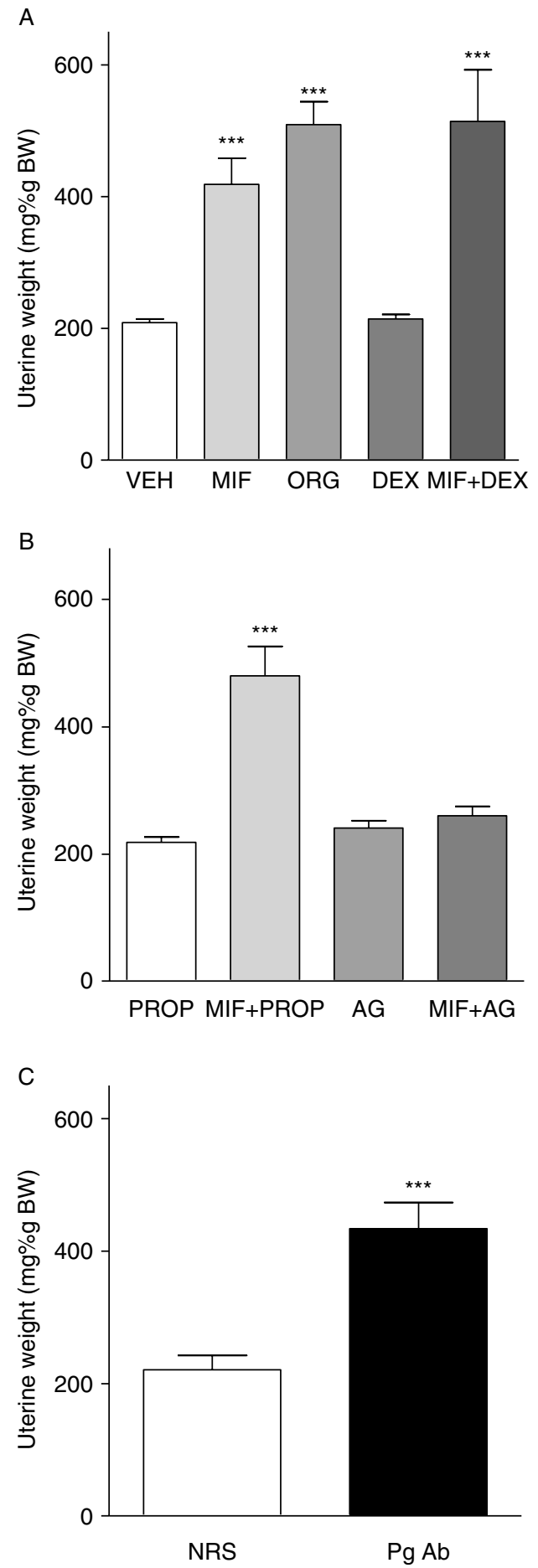

Figure 5 Uterine weights expressed as percentage of total body weight $(\mathrm{mg} \% \mathrm{~g} \mathrm{BW})$ of rats from experiments 1 and 2 (A), 3 (B), and 4 (C). Each value is the mean \pm s.E.M. of six to nine rats. ${ }^{* * *} P<0.001$ compared to controls. One-way ANOVA (ANOVA I) and Bonferroni's test were used for multiple comparisons.

Both antagonists administered at proestrus showed comparable effects on serum PRL concentrations measured in estrus, suggesting that the blockage of Pg actions is responsible for the surge of PRL observed at estrus. However, as the administration of the specific anti-Pg antibody did not modify the release of PRL, one can suggest that indeed it is the blockade of circulating glucocorticoids that is responsible for the hypersecretion of PRL during estrus. This speculation is further supported by the fact that DEX partially suppressed the secretion of PRL during proestrus and decreased the basal concentration of PRL during estrus. Both effects were reverted by MIF, underscoring its antiglucocorticoid action. Nonetheless, an inhibitory action of circulating Pg on PRL secretion during proestrus cannot be ruled out since both antagonists (i.e. MIF and ORG) induced similar increases in levels of serum PRL during estrus and, additionally, the steroid synthesis inhibitor AG mimicked the effects of MIF on PRL secretion but also affected Pg secretion. It is interesting to underline the additive effect of MIF and AG on PRL production during estrus, suggesting that both drugs are acting via different mechanisms, blocking Pg and glucocorticoid receptors, and inhibiting steroidal synthesis, respectively. AG is used to inhibit the synthesis of adrenal and ovarian steroids by affecting the function of enzymes involved in the production of corticoids. Its use is mainly as an antiglucocorticoid agent to diminish corticoid production in several clinical conditions as chemical adrenalectomy (Lerner et al. 1984, Mancini et al. 2010). Several studies have shown the decrease in serum corticosterone evoked by AG in rats (Mazzocchi et al. 1987, Robba et al. 1987). In this study, AG also reduced $\mathrm{Pg}$ secretion but only during estrus and in a partial manner; we can then assume that its antiglucocorticoid, but not its antiprogestin action, is a prevalent mechanism.

It is important to note that the regulation of PRL secretion is clearly different during proestrus and estrus. In our experiments, the blockade of the steroid hormones by MIF and ORG are already effective during proestrus, since their effects on serum Pg are evident and similar to those during estrus. Additionally, our previous studies demonstrated that MIF is able to modify hormone secretion as soon as $5 \mathrm{~h}$ after its administration (Caron et al. 1997, Salicioni et al. 1997). Thus, it seems that circulating hormones during proestrus are regulating PRL secretion during estrus. In fact, preventing the effect of corticoids during proestrus with MIF or ORG evoked increase in serum PRL on estrus without modifications during proestrus.

Szawka \& Anselmo-Franci (2004) have concluded that the secondary peak of PRL occurring during estrus is estrogen-dependent. Accordingly, in our previous studies, we have shown that circulating adrenal corticoids clearly inhibited estrogen-induced PRL release (Caron et al. 1994). Our present results demonstrate that the inhibitory effect of circulating corticoids is present during estrus, when PRL secretion is also triggered by estrogens. 

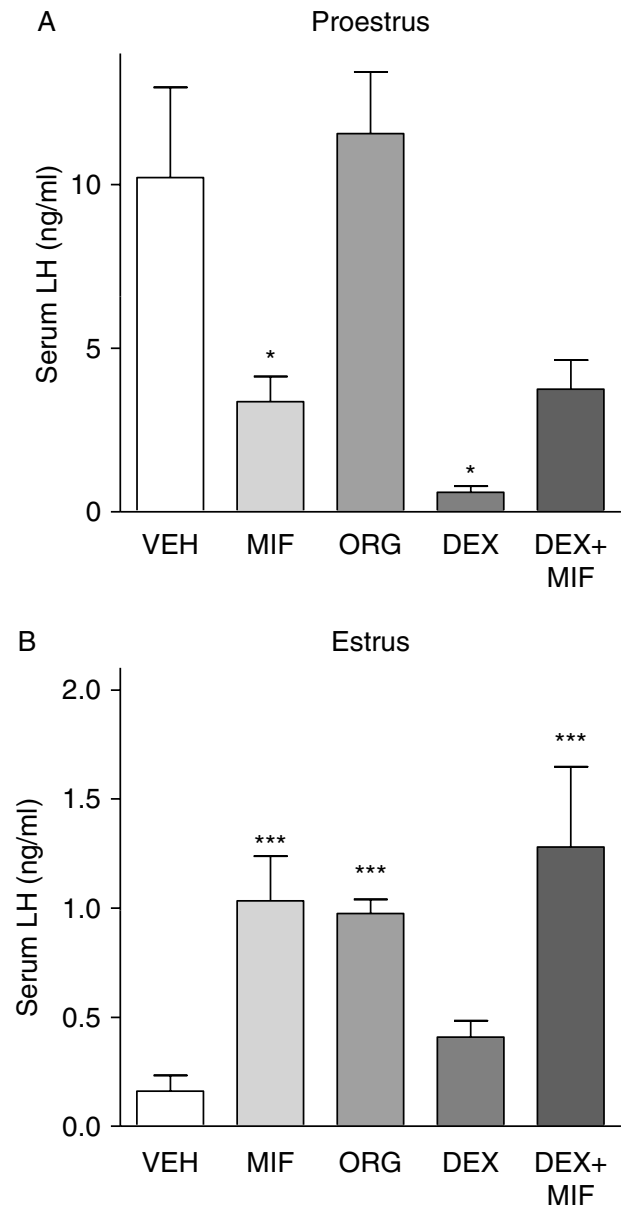

Figure 6 Serum concentrations of $\mathrm{LH}$ in rats treated during proestrus with mifepristone (MIF), ORG-33628 (ORG), dexamethasone (DEX), or DEX + MIF. Results are shown at $1800 \mathrm{~h}$ proestrus (A) and estrus (B). Control groups are vehicle-administered rats. Each value is the mean \pm S.E.M. of six to nine rats. ${ }^{*} P<0.05$ and ${ }^{* * *} P<0.001$ compared to control. One-way ANOVA (ANOVA I) and Bonferroni's test were used for multiple comparisons.

Both Pg antagonists, MIF and ORG, increased serum Pg levels supporting the inhibitory feedback of Pg on its own secretion as previously described by Telleria \& Deis (1994). This increased Pg concentration is not supposed to affect PRL secretion since Pg receptors are occupied by the antagonists. A different situation is observed with DEX treatment, which is able to diminish Pg concentrations and to stimulate corticoid receptors at the same time, likely accounting for the dramatic decrease in PRL during proestrus when Pg is stimulatory, and during estrus when corticoids are inhibitory. Moreover, the removal of the action of circulating Pg by the specific antiserum did not modify serum PRL either at proestrus or at estrus, even when free circulating levels of Pg were significantly diminished, suggesting that $\mathrm{Pg}$ in circulation is not active in blocking PRL secretion.
We studied the uterine ballooning as a surrogate indicator of the efficacy of the treatments with antihormones in blocking the actions of Pg. Both Pg antagonists, MIF and ORG, significantly increased uterine ballooning, while DEX had no effect. Interestingly, the Pg antiserum evoked a significant increase in uterine weight, demonstrating its ability to bind circulating Pg, thus preventing its counteractive effect on estrogen activity in the uterus. Taken together, these results indicate that all antiprogesterone treatments used in our study are comparable in terms of their effects on a target tissue such as the uterus.

The effects of Pg antagonists on gonadotropin secretion during the estrous cycle have been well documented (Sanchez-Criado et al. 1993, 1994). It has previously been demonstrated that when administered at proestrus, MIF suppressed the preovulatory surge of the pituitary gonadotropins LH and FSH (Szabo et al. 1996, Tebar et al. 1996). In this study, the administration of the antagonist in a single dose at proestrus, as expected, decreased the preovulatory surge of $\mathrm{LH}$. Thus, it becomes clear from several studies using MIF that Pg and glucocorticoids at proestrus play an important role in the preovulatory release of gonadotropins (Brann et al. 1991, Tebar et al. 1995) and PRL (Telleria et al. 1997). In addition, the central action of $\mathrm{Pg}$ and/or glucocorticoids on the afternoon of proestrous seems to abort the neural signal for successive LH and PRL surges, as indicated by the hypersecretion of LH and PRL that we observed on the afternoon of estrus in animals receiving MIF at proestrus.

It has previously been concluded that the increase in $\mathrm{Pg}$ production observed on the afternoon of estrous in MIFtreated rats paralleled the hypersecretion of $\mathrm{LH}$ and $\mathrm{PRL}$ in the same animals, suggesting that most likely Pg increases at estrus in response to a trophic ovarian action of $\mathrm{LH}$ and/or PRL (Telleria et al. 1997). This can be the case in our rats at estrus, since we observed a parallel augment of PRL, LH, and $\mathrm{Pg}$. However, during proestrus, $\mathrm{Pg}$ is also increased but in the absence of simultaneous high levels of circulating PRL and LH, suggesting a rather direct effect of MIF on ovarian production of $\mathrm{Pg}$ as previously demonstrated in pregnant rat ovaries (Telleria \& Deis 1994).

\section{Conclusion}

Our study provides evidence suggesting that PRL secretion at estrus is inhibited by circulating corticoids during the previous proestrus, supporting an additional role of the adrenal gland on PRL regulation.

\section{Materials and Methods}

\section{Animals}

Virgin female rats bred in our laboratory (originally Wistar strain), 80-90 days old and weighing 180-220 g, were used. They were kept under controlled lighting (lights on 
0600-2000 h) and temperature $\left(22-24^{\circ} \mathrm{C}\right)$; standard rat chow (Nutric, Córdoba, Argentina) and water were available ad libitum. All the animals were shown by vaginal smears to have had at least three successive 4-day cycles. Vaginal smears were observed at $0800 \mathrm{~h}$ including the experimental days (proestrus and estrus) immediately before the administration of the different drugs.

\section{Experimental protocols}

In the first experiment, cycling rats were injected s.c. with vehicle at $1000 \mathrm{~h}$ and MIF $(n=9)$ or ORG $(n=7)$ at $1200 \mathrm{~h}$, or they were injected s.c. with DEX at $1000 \mathrm{~h}$ and MIF $(n=6)$ or vehicle $(n=6)$ at $1200 \mathrm{~h}$ on the proestrous day. The respective control group $(n=9)$ received vehicle at $1000 \mathrm{~h}$ and at $1200 \mathrm{~h}$ on the proestrous day. The timing of the administration of both antagonists was established based on the observation of Atkinson \& Waddell, showing that Wistar rats kept in a $14 \mathrm{~h}$ light:10 h darkness cycle have a diurnal increase in plasma corticosterone during proestrus starting $4 \mathrm{~h}$ after lights on. Thus, administering the antagonist at $1200 \mathrm{~h}$ on proestrus allows to block at the receptor level the effects of the main surge of corticosterone occurring during the afternoon of proestrous (Atkinson \& Waddell 1997).

To further investigate the role of circulating steroids in the regulation of $\mathrm{PRL}$ secretion during the day of estrus, in a second experiment, cycling rats on proestrus were administered at $1000 \mathrm{~h}$ with the steroid synthesis inhibitor AG or with its vehicle PROP, whereas MIF or its vehicle were given at $1200 \mathrm{~h}$.

Finally, to distinguish the antiprogesterone from the antiglucocorticoid activity of MIF, a third experiment was designed including cycling rats administered with four doses of $50 \mu \mathrm{l}$ of a specific Pg-Ab at 0800 and $1200 \mathrm{~h}$ on proestrus and estrus $(n=9)$ or normal rabbit serum as control $(n=8)$.

\section{Blood sampling and uterine weighing}

All the animals' blood was sampled through a small incision of the tip of the tail under slight ether anesthesia at $1800 \mathrm{~h}$ on the proestrous day and were decapitated $24 \mathrm{~h}$ later (at $1800 \mathrm{~h}$ on estrus). Preliminary experiments from our laboratory did not find differences in serum PRL levels from samples obtained by the cut of the tail or by decapitation (Valdez et al. 2007). All work was in accordance with the NIH Guide for the Care and Use of Laboratory Animals (NIH publication No. 86-23, revised 1985). Blood was allowed to clot at room temperature and serum was separated and stored frozen $\left(-20^{\circ} \mathrm{C}\right)$ until assayed for hormone level determination. Immediately after decapitation, the uterine horns were dissected and weighed as a measurement of uterine ballooning to assess for biological effects of ovarian steroids. The uterine weights were expressed as percentage of total body weight.

\section{Drug treatments}

MIF (RU-38486; 17 $\beta$-hydroxy-11 $\beta$ (4-dimethylamino-phenyl) $17 \alpha$-(prop-1-ynyl) estra-4,9-dien-3-one, Sigma) and ORG33668 (N.V. Organon, Amsterdam, The Netherlands) were dissolved in sunflower seed oil at $5 \mathrm{mg} / \mathrm{ml}$ and injected s.c. at a dose of $5 \mathrm{mg} / \mathrm{kg}$. DEX (Sigma) was dissolved in sunflower seed oil at $2 \mathrm{mg} / \mathrm{ml}$ and injected s.c. at a dose of $2 \mathrm{mg} / \mathrm{kg}$. AG [3-(4-aminophenyl)-3-ethyl-piperidine-2,6-dione] (Sigma) was dissolved in PROP (propane-1,2-diol) at $75 \mathrm{mg} / \mathrm{ml}$ and injected s.c. at a dose of $150 \mathrm{mg} / \mathrm{kg}$. Pg antiserum was raised in rabbits in our laboratory (Deis et al. 1989, Caron et al. 1994, 1997, Valdez et al. 2007) and kept frozen $\left(-20^{\circ} \mathrm{C}\right)$ in aliquots until administration. In a previous work, we measured the capacity of the antiserum to bind $\left[{ }^{3} \mathrm{H}\right] \mathrm{Pg}$ and found that $1 \mu \mathrm{l}$ antiserum binds $\sim 60 \mathrm{ng}(0.19 \mathrm{nmol}) \mathrm{Pg}$ and $0.3 \mathrm{ng}(0.86 \mathrm{pmol})$ corticosterone in a volume of $1 \mathrm{ml}$. Thus, the quantity of antiserum injected $(100 \mu \mathrm{l} /$ day) was more than sufficient to neutralize all circulating Pg without interfering with the action of corticoids (Caron et al. 1994).

\section{Hormone determinations}

PRL, LH, and FSH were measured by double-antibody RIA using materials provided by $\mathrm{Dr}$ A $\mathrm{F}$ Parlow, NIADDK Rat Pituitary Hormone Distribution Program. The hormones were radioiodinated using the chloramine-T method and purified by passage through Sephadex G75. The results are expressed in terms of the rat PRL RP-3, rat LH RP-3, or rat FSH RP-2 standard preparations. Assay sensitivity was $0.5 \mu \mathrm{g} / \mathrm{l}$ serum and interand intra-assay coefficients of variation were $<10 \%$ for the three hormones. Serum Pg was measured using a RIA developed in our laboratory (Bussmann \& Deis 1979) with antiserum raised in rabbits against Pg-11-BSA conjugate. Assay sensitivity was $<1.6 \mathrm{nmol} / \mathrm{l}$ serum, and inter- and intra-assay coefficients of variation were $<10 \%$.

\section{Statistical analysis}

Values are given as mean \pm S.E.M. of 6-12 animals per group. All statistical analysis was performed using the GraphPad Prism 5.01 software (GraphPad Software, Inc., La Jolla, CA, USA). One-way ANOVA (ANOVA I) was used for analysis of the effects of the treatments. Post hoc comparisons between means were made by Bonferroni's test. When variances were not homogeneous, logarithmic transformation of data was applied. Differences were considered significant for $P<0.05$.

\section{Declaration of interest}

The authors declare that there is no conflict of interest that could be perceived as prejudicing the impartiality of the research reported.

\section{Funding}

This work was supported by a Grant (PID 312210088) from Consejo Nacional de Investigaciones Científicas y Técnicas (CONICET), Argentina.

\section{Acknowledgements}

The authors wish to thank Dr A F Parlow from the NHPP, for rat RIA reagents, and to $\mathrm{Mr}$ Juan Rosales for his excellent 
technical assistance. This paper is dedicated to the memory of Dr Ricardo P Deis, deceased on 26 April 2008, who was a pioneer on PRL and lactation physiology and whose mentorship, counsel, and suggestions greatly enriched this work.

\section{References}

Arbogast LA \& Ben Jonathan N 1988 The preovulatory prolactin surge: an evaluation of the role of dopamine. Endocrinology 123 2690-2695. (doi:10.1210/endo-123-6-2690)

Arbogast LA \& Ben Jonathan N 1990 The preovulatory prolactin surge is prolonged by a progesterone-dependent dopaminergic mechanism. Endocrinology 126 246-252. (doi:10.1210/endo-126-1-246)

Atkinson HC \& Waddell BJ 1997 Circadian variation in basal plasma corticosterone and adrenocorticotropin in the rat: sexual dimorphism and changes across the estrous cycle. Endocrinology 138 3842-3848. (doi:10.1210/en.138.9.3842)

Brann DW, Putnam CD \& Mahesh VB 1990 Corticosteroid regulation of gonadotropin and prolactin secretion in the rat. Endocrinology 126 159-166. (doi:10.1210/endo-126-1-159)

Brann DW, Putnam CD \& Mahesh VB 1991 Validation of the mechanisms proposed for the stimulatory and inhibitory effects of progesterone on gonadotropin secretion in the estrogen-primed rat: a possible role for adrenal steroids. Steroids 56 103-111. (doi:10.1016/0039-128X(91) 90132-F)

Bussmann LE \& Deis RP 1979 Studies concerning the hormonal induction of lactogenesis by prostaglandin $\mathrm{F}_{2 \alpha}$ in pregnant rats. Journal of Steroid Biochemistry 11 1485-1489. (doi:10.1016/0022-4731(79)90125-0)

Butcher RL, Collins WE \& Fugo NW 1974 Plasma concentration of LH, $\mathrm{FSH}$, prolactin, progesterone and estradiol-17beta throughout the 4-day estrous cycle of the rat. Endocrinology 94 1704-1708. (doi:10.1210/ endo-94-6-1704)

Caligaris L, Astrada JJ \& Taleisnik S 1974 Oestrogen and progesterone influence on the release of prolactin in ovariectomized rats. Journal of Endocrinology 60 205-215. (doi:10.1677/joe.0.0600205)

Caron RW, Salicioni AM \& Deis RP 1994 Mifepristone treatment demonstrates the participation of adrenal glucocorticoids in the regulation of oestrogen-induced prolactin secretion in ovariectomized rats. Journal of Steroid Biochemistry and Molecular Biology 48 385-389. (doi:10.1016/0960-0760(94)90079-5)

Caron RW, Salicioni AM \& Deis RP 1997 Regulation of prolactin secretion by adrenal steroids in oestrogen-treated ovariectomized rats: participation of endogenous opioid peptides. Neuropharmacology 36 1433-1438. (doi:10.1016/S0028-3908(97)00109-3)

Deis RP, Leguizamon E \& Jahn GA 1989 Feedback regulation by progesterone of stress-induced prolactin release in rats. Journal of Endocrinology 120 37-43. (doi:10.1677/joe.0.1200037)

Dickmeis T 2009 Glucocorticoids and the circadian clock. Journal of Endocrinology 200 3-22. (doi:10.1677/JOE-08-0415)

Freeman ME, Reichert LE Jr \& Neill JD 1972 Regulation of the proestrus surge of prolactin secretion by gonadotropin and estrogens in the rat. Endocrinology 90 232-238. (doi:10.1210/endo-90-1-232)

Freeman ME, Kanyicska B, Lerant A \& Nagy G 2000 Prolactin: structure, function, and regulation of secretion. Physiological Reviews $\mathbf{8 0}$ 1523-1631.

Gala RR 1990 The physiology and mechanisms of the stress-induced changes in prolactin secretion in the rat. Life Sciences 46 1407-1420. (doi:10.1016/0024-3205(90)90456-2)

Kiem DT, Fekete MI \& Makara GB 1995 Diurnal alteration in opiate effects on the hypothalamo-pituitary-adrenal axis: changes in the mechanism of action. European Journal of Pharmacology 272 145-150. (doi:10.1016/ 0014-2999(94)00639-O)

Kloosterboer HJ, Deckers GH, de Gooyer ME, Dijkema R, Orlemans EO \& Schoonen WG 1995 Pharmacological properties of a new selective antiprogestagen: Org 33628. Annals of the New York Academy of Sciences 761 192-201. (doi:10.1111/j.1749-6632.1995.tb31379.x)

Knox KL \& Schwartz NB 1992 RU486 blocks the secondary surge of folliclestimulating hormone in the rat without blocking the drop in serum inhibin. Biology of Reproduction 46 220-225. (doi:10.1095/biolreprod46.2.220)
Knox KL \& Schwartz NB 1993 Pituitary in vitro LH and FSH secretion after administration of the antiprogesterone RU486 in vivo. Recent Progress in Hormone Research 48 523-530.

Lerner A, Lee PC \& Lebenthal E 1984 Chemical adrenalectomy by aminoglutethimide and the pancreas in suckling rats. American Journal of Physiology 247 G346-G351.

Mancini T, Porcelli T \& Giustina A 2010 Treatment of Cushing disease: overview and recent findings. Therapeutics and Clinical Risk Management 6 505-516. (doi:10.2147/TCRM.S12952)

Mazzocchi G, Robba C, Meneghelli V \& Nussdorfer GG 1987 Effects of $\mathrm{ACTH}$ and aminoglutethimide administration on the morphological and functional responses of rat adrenal zona fasciculata to a prolonged treatment with 4-aminopyrazolo-pyrimidine. Journal of Anatomy $\mathbf{1 5 4}$ $55-61$.

Neill JD 1970 Effect of "stress" on serum prolactin and luteinizing hormone levels during the estrous cycle of the rat. Endocrinology 87 1192-1197. (doi:10.1210/endo-87-6-1192)

Philibert D \& Teutsch G 1990 RU 486 development. Science 247622. (doi:10.1126/science.2300819)

Putnam CD, Brann DW \& Mahesh VB 1991 Acute activation of the adrenocorticotropin-adrenal axis: effect on gonadotropin and prolactin secretion in the female rat. Endocrinology 128 2558-2566. (doi:10. 1210/endo-128-5-2558)

Robba C, Mazzocchi G \& Nussdorfer GG 1987 Effects of a prolonged treatment with aminoglutethimide on the zona fasciculata of rat adrenal cortex: a morphometric investigation. Cell and Tissue Research $\mathbf{2 4 8}$ 519-525. (doi:10.1007/BF00216478)

Salicioni AM, Caron RW \& Deis RP 1997 Participation of both adrenergic and opioidergic systems in the negative feedback of adrenal progesterone on LH secretion. European Journal of Pharmacology 332 283-287. (doi:10.1016/S0014-2999(97)01082-0)

Sanchez-Criado JE, Bellido C, Lopez FJ \& Galiot F 1992 Antiprogesterone RU486 induces dissociation of $\mathrm{LH}$ and FSH secretion in the cyclic rat: effect of anti-inhibin serum. Journal of Endocrinology 134 43-49. (doi:10.1677/joe.0.1340043)

Sanchez-Criado JE, Galiot F, Bellido C, Gonzalez D \& Tebar M 1993 Hypothalamus-pituitary-ovarian axis in cyclic rats lacking progesterone actions. Biology of Reproduction 48 916-925. (doi:10.1095/biolreprod48.4.916)

Sanchez-Criado JE, Hernandez G, Bellido C, Gonzalez D, Tebar M, Diaz-Cruz MA \& Alonso R 1994 Periovulatory LHRH, LH and FSH secretion in cyclic rats treated with RU486: effects of exogenous LHRH and LHRH antagonist on LH and FSH secretion at early oestrus. Journal of Endocrinology 141 7-14. (doi:10.1677/joe.0. 1410007)

van der Schoot P, Bakker GH \& Klijn JG 1987 Effects of the progesterone antagonist RU486 on ovarian activity in the rat. Endocrinology 121 1375-1382. (doi:10.1210/endo-121-4-1375)

Shimokawa N, Kato Y, Imai K \& Wakabayashi K 1990 Changes in content of prolactin mRNA during the rat estrous cycle. Experimental and Clinical Endocrinology 96 8-14. (doi:10.1055/s-0029-1210982)

Smith MS, Freeman ME \& Neill JD 1975 The control of progesterone secretion during the estrous cycle and early pseudopregnancy in the rat: prolactin, gonadotropin and steroid levels associated with rescue of the corpus luteum of pseudopregnancy. Endocrinology 96 219-226. (doi:10. 1210/endo-96-1-219)

Spitz IM \& Bardin CW 1993 Clinical pharmacology of RU 486 - an antiprogestin and antiglucocorticoid. Contraception 48 403-444. (doi:10.1016/0010-7824(93)90133-R)

Szabo M, Knox KL, Ringstrom SJ, Perlyn CA, Sutandi S \& Schwartz NB 1996 Mechanism of the inhibitory action of RU486 on the secondary folliclestimulating hormone surge. Endocrinology 137 85-89. (doi:10.1210/en. 137.1.85)

Szawka RE \& Anselmo-Franci JA 2004 A secondary surge of prolactin on the estrus afternoon. Life Sciences 75 911-922. (doi:10.1016/j.Ifs.2004. 01.027)

Tebar M, Bellido C \& Sanchez-Criado JE 1995 Luteinizing hormone (LH) and corticosterone in proestrous afternoon restore the follicle-stimulating hormone secretion at early estrus in adrenalectomized LH-releasing hormone antagonist-treated rats. Biology of Reproduction 52 63-67. (doi:10.1095/biolreprod52.1.63) 
Tebar M, Ruiz A \& Sanchez-Criado JE 1996 Hypersecretion of folliclestimulating hormone (FSH) on estrous afternoon in rats treated with RU486 in proestrus. Cellular and Molecular Neurobiology 16 421-426. (doi:10.1007/BF02088107)

Telleria CM \& Deis RP 1994 Effect of RU486 on ovarian progesterone production at pro-oestrus and during pregnancy: a possible dual regulation of the biosynthesis of progesterone. Journal of Reproduction and Fertility 102 379-384. (doi:10.1530/jrf.0.1020379)

Telleria CM, Mezzadri MR \& Deis RP 1997 Fertility impairment after mifepristone treatment to rats at proestrus. Actions on the hypothalamichypophyseal-ovarian axis. Contraception 56 267-274. (doi:10.1016/ S0010-7824(97)00137-6)

Uilenbroek JT 1991 Hormone concentrations and ovulatory response in rats treated with antiprogestagens. Journal of Endocrinology 129 423-429. (doi:10.1677/joe.0.1290423)
Valdez SR, Penissi AB, Deis RP \& Jahn GA 2007 Hormonal profile and reproductive performance in lactation deficient (OFA hr/hr) and normal (Sprague-Dawley) female rats. Reproduction 133 827-840. (doi:10. 1530/REP-06-0032)

Yen SH \& Pan JT 1998 Progesterone advances the diurnal rhythm of tuberoinfundibular dopaminergic neuronal activity and the prolactin surge in ovariectomized, estrogen-primed rats and in intact proestrous rats. Endocrinology 139 1602-1609. (doi:10.1210/en.139.4.1602)

Received 30 March 2011

First decision 21 April 2011

Revised manuscript received 7 June 2011

Accepted 22 June 2011 